\title{
A FILOSOFIA FORA DAS GRADES (CURRICULARES): a Lei 10.639/03 e os desafios para um ensino de filosofia antirracista
}

Diego dos Santos Reis

\section{Resumo}

O ensaio objetiva discutir os pressupostos epistêmicos, políticos e culturais do currículo de filosofia, a partir da implementação da Lei 10.639/03 e da crítica endereçada ao racismo epistêmico. Discutem-se, nessa análise, desde a perspectiva teórica do pensamento decolonial, os efeitos, os rastros e as estruturas persistentes da colonialidade no ensino de filosofia e, de modo especial, nos currículos. Trata-se, ademais, de problematizar o descompasso entre as tendências acadêmicas hegemônicas de perspectiva eurocentradas, que desconsideram as determinações geopolíticas na construção do conhecimento, e os saberes e experiências de populações africanas, afrodiaspóricas, indígenas e latino-americanas. Argumenta-se, por fim, que o projeto ancorado nos valores da modernidade/colonialidade europeia opera pela subalternização e silenciamento dos conhecimentos produzidos a partir de outras matrizes corpo-políticas, invalidando-as pela via do epistemicídio. Pensar o currículo de filosofia em bases decoloniais e antirracistas exige, portanto, que se questionem as premissas norteadoras deste projeto étnico, sexual e racialmente excludente.

Palavras-chave: decolonialidade; racismo; lei 10.639/03; currículo de filosofia; colonialidade do saber.

PHILOSOPHY OUTSIDE THE CURRICULAR GRIDS: the Law 10.639/03 and the challenges for an anti-racist philosophy teaching

\begin{abstract}
The essay aims to discuss the epistemic, political and cultural assumptions of the philosophy curriculum from the implementation of Law 10.639/03 and its critique to epistemic racism. The effects, traces and persistent structures of coloniality in philosophy teaching - in particular, through philosophy curriculum are discussed in this analysis, from the theoretical perspective of decolonial thinking. It is also a matter of problematizing the mismatch between Latin American reality and the hegemonic academic trends of a Eurocentric perspective, which disregard the geopolitical determinations in knowledge construction and the knowledge of indigenous, Latin American and African diaspora people. Finally, it is discussed that this project is based on values of European modernity/coloniality that generate the subalternization and silencing of knowledge produced from other body-politics matrices, invalidating them by epistemicide. Therefore, thinking about philosophy curriculum on a decolonial and anti-racist basis requires to question the guiding premises of an ethnic, sexual and racially excluding project.
\end{abstract}

Keywords: decoloniality; racism; law 10.639/03; philosophy curriculum; coloniality of knowing.

FILOSOFÍA FUERA DE MALLAS CURRICULARES: la Ley 10.639/03 y los desafíos para una enseñanza filosófica antirracista

Resumen

El ensayo tiene como objetivo discutir los supuestos epistémicos, políticos y culturales del currículo de filosofía, a partir de la implementación de la Ley 10.639/03 y de la crítica dirigida al racismo epistémico. En este análisis, desde una perspectiva teórica decolonial, se discuten los efectos, las huellas y las estructuras persistentes de la colonialidad en la enseñanza de la filosofía y, especialmente, en los currículos. Se trata también de problematizar la brecha entre las tendencias académicas hegemónicas ancladas en una perspectiva eurocéntrica, que son indiferentes a las determinaciones geopolíticas en la construcción del 
conocimiento y los conocimientos y experiencias de poblaciones africanas, afrodiaspóricas, indígenas y latinoamericanas. Finalmente, se argumenta que el proyecto anclado en los valores de la modernidad/colonialidad europea opera subordinando y silenciando los conocimientos producidos desde otras matrices cuerpo-políticas, invalidando estos saberes a través del epistemicidio. Pensar el currículo de filosofía desde una base descolonial y antirracista requiere, por tanto, cuestionar las premisas rectoras de un proyecto étnico, sexual y racialmente exclusivo.

Palabras clave: decolonialidad; racismo; ley 10.639/03; currículos de filosofía; colonialidad del saber.

\title{
INTRODUÇÃO
}

\author{
Em todos os niveis do ensino brasileiro - primário, \\ secundário, universitário - o elenco das matérias ensinadas, \\ como se executasse o que havia previsto Sílvio Romero, \\ constitui um ritual da formalidade e da ostentação das salas \\ da Europa, e, mais recentemente, dos Estados Unidos. Se \\ consciência é memória e futuro, quando e onde está a memória \\ africana, parte inalienável da consciência brasileira no \\ curriculo escolar? \\ Abdias Nascimento, O genocídio do negro brasileiro: processo \\ de um racismo mascarado
}

No campo da educação, os debates relativos às questões étnico-raciais têm sido levados a cabo, sobretudo, nas áreas de políticas educacionais, da formação docente e dos currículos. A discussão racial, impulsionada pelas críticas às desigualdades, ao racismo estrutural da sociedade brasileira e ao genocídio negro em curso, pauta, assim, um conjunto de problematizações no âmbito da educação, conferindo-lhe os contornos políticos em vinculação intrínseca ao campo social.

O aumento expressivo de estudos voltados para essa temática atesta, principalmente nos últimos decênios, não apenas o vigor de um campo em permanente expansão, mas os reflexos de lutas sociais e políticas que redimensionam teorias e práticas pedagógicas. Se a pauta e as agendas raciais têm reconfigurado o campo dos debates educacionais, talvez esse movimento aponte para redefinição interna não de uma subárea, mas do próprio campo, em seu conjunto, tensionado por perspectivas e epistemologias que colocam em diálogo "o chão da escola" e a realidade multiétnica e plurirracial da sociedade brasileira. Pois as instituições educativas não passam incólumes, evidentemente, às tensões que provocam sismos de amplas escalas em territórios monoepistêmicos e monoculturais, com impactos inegáveis nas práticas de ensino, nos currículos e na formação docente.

Esse ensaio tem por objetivo refletir sobre o questionamento do monopólio epistêmicocultural nos currículos de filosofia, mormente após a promulgação da Lei $10.639 / 03^{1}$ e suas

\footnotetext{
${ }^{1}$ Sancionada pela Presidência da República em janeiro de 2003, a Lei 10.639/03, que alterou a Lei de Diretrizes e Bases da Educação Nacional, tornou obrigatória a inclusão de História e Culturas africana e afrobrasileira nos currículos escolares de todos os níveis de ensino no país. A Lei, que viria a ser alterada novamente em 2008, com a introdução da obrigatoriedade do estudo da História e Cultura dos povos indígenas (redação proposta pela Lei 11.645), é fruto de inúmeras lutas contra o apagamento dos referenciais culturais e da historia da diáspora africana no Brasil e da necessidade de contemplar matrizes culturais invisibilizadas no processo educativo formal. Cf. BRASIL. Ministério da Educação. Lei 10.639, de 19 de janeiro de 2003. Altera a Lei no 9.394, de 20 de dezembro de 1996, que estabelece as diretrizes e bases da educação nacional, para incluir no currículo oficial
}

Revista Teias v. 23・n. $68 \bullet$ jan./mar. 2022• 
reverberações legais e simbólicas para o redesenho de percursos formativos e curriculares. Tratase de pensar a construção de itinerários, práticas pedagógicas e currículos orientados para uma educação antirracista, intercultural e decolonial, isto é, a necessária articulação entre teorias contrahegemônicas e práticas educativas específicas, a fim de propor estratégias capazes de implementar, efetivamente, o disposto na Lei. Além disso, reitera-se a necessária reavaliação político-epistêmica dos currículos, de modo a colocar em prática ações que operem o deslocamento da invisibilização negra à inviabilização de um projeto racista/patriarcal, cuja gramática tem subsidiado, historicamente, o funcionamento do sistema-mundo capitalista/moderno/colonial.

Analisar o problema dos fundamentos e das práticas educativas a partir de uma abordagem decolonial, especialmente no que se refere ao ensino de filosofia e seu currículo, requer que seja adotada uma lente antirracista, capaz de colocar em perspectiva sistemas de dominação e opressão interseccionados, ancorados na hierarquização de humanidades, saberes e experiências. Pois não é fortuito que essa hierarquização sustente um sistema de posições, estratificado, que opera em prejuízo ou privilégio de determinados grupos raciais/sexuais - com a produção de centros e periferias do conhecimento; acesso facilitado ou obstaculizado aos direitos sociais; reconhecimento ou negação ontológica de sujeitos epidermicamente inferiorizados.

Aqui, logo de saída, é preciso remeter aos escritos de Renato Noguera (2012, 2014) e de Wanderson Flor do Nascimento (2012, 2015), cujos trabalhos aprofundaram, de modo inaugural, uma série de reflexões sobre relações raciais e ensino de filosofia no Brasil, com ênfase nas repercussões da Lei 10.639/03 na formação docente para a educação básica e nos estudos das africanidades nos currículos de filosofia. A abertura de caminhos levada a cabo pelos filósofos merece destaque, ainda, por tensionar abordagens hegemônicas, a fim de apontar outros modos de compreensão da produção do conhecimento e da história da filosofia, com impacto significativo no que concerne à discussão do cânone filosófico, das práticas de ensino afrorreferenciadas e das epistemologias não ocidentais.

Esse movimento, longe de circunscrever-se a uma única área da filosofia, impõe um processo autorreflexivo a todo campo, com dimensões críticas inequívocas para o ensino de filosofia, mas também para a discussão acerca das filosofias brasileira, latino-americana e africana, para o questionamento da hierarquizações de saberes, humanidades e geopolíticas da (re)produção do conhecimento filosófico.

Ao sublinhar os perigos de uma história única, nas trilhas de Adichie (2019), e a invisibilização dos lugares, espaços e territórios de produção do pensamento filosófico, destaca-se como a associação de práticas de dominação, como o colonialismo e a escravidão, com práticas discursivas revestidas pela "cientificidade" produziu, historicamente, significados e sentidos que serviram para legitimar as estruturas de opressão - com esteio nas diferenças de raça e gênero, convertidas em desigualdades hierarquizadas. Sem levar esse fato em consideração, incorre-se no risco de reiterar os dualismos que não cessaram de inferiorizar os corpos, racializados e generificados, em detrimento da defesa uma razão/mente/alma e de um pensamento universais. Pois sabe-se que, ao reafirmar a racionalidade e a objetividade de seus discursos, para além do domínio mítico ou religioso, a filosofia ocidental pretendeu operar como centro positivado, monorracional, que exclui de seu repertório uma série de outras possibilidades e lógicas epistêmicas do discurso filosófico, que não sejam aquelas produzidas e legitimadas pelo ocidente.

da Rede de Ensino a obrigatoriedade da temática "História e Cultura Afro-Brasileira", e dá outras providências. Disponível em: <https://www.planalto.gov.br/ccivil_03/Leis/2003/L10.639.htm>. Acesso em: 20 ago. 2020.

Revista Teias v. 23・n. $68 \bullet$ jan./mar. 2022• 


\section{CURRÍCULO DE FILOSOFIA, COLONIALIDADE E RELAÇÕES RACIAIS}

No Brasil, o genocídio perpetrado contra populações originárias, o sequestro e a escravização negro-africana e o extermínio de corpos e subjetividades racialmente inferiorizados marcaram decisivamente a experiência colonial. A colonialidade, enquanto matriz de poder que funda a modernidade, baseia-se na centralidade da ideia da raça como dimensão estruturante da lógica moderno/colonial (QUIJANO, 2005), que se converte em princípio organizador das relações intersubjetivas, dos regimes de trabalho, da sexualidade e de produção do conhecimento. Ela apoia-se no racismo como sistema de poder, que garante não só a supremacia dos corpos brancos em relação a outros sujeitos racialmente marcados, mas define também os regimes de produção e difusão de conhecimentos legítimos, válidos e socialmente valorizados.

$\mathrm{Na}$ contramão das múltiplas hierarquizações do humano, que marcam quais corpos são mais propensos às violências e menos aptos à produção de conhecimento válido, a reflexão acerca da educação antirracista e das relações raciais no país deve iluminar não apenas as fissuras que cindem os repertórios e os projetos em disputa, mas também os enfrentamentos plurais em nome de outras possibilidades de vida, de sociedade e de pensamento.

A perspectiva decolonial propõe, nesse sentido, uma crítica contundente ao eurocentrismo, apontando na universalidade o seu caráter etnocêntrico e geopoliticamente situado, cujo pacto narcísico, firmado desde a Europa, reconhece apenas este modelo civilizatório e epistêmico como racionalidade verdadeira e legítima a ser difundida (REIS, 2020). O eurocentrismo torna-se, por conseguinte, "[...] uma metáfora para descrever a colonialidade do poder, na perspectiva da subalternidade. Da perspectiva epistemológica, o saber e as histórias locais europeias foram vistos como projetos globais [...], narrada de uma perspectiva que situa a Europa como ponto de referência e de chegada" (MIGNOLO, 2003, p. 41). A colonialidade do poder e a colonialidade do saber perpetuam-se, assim, pela via de uma série de justificativas "naturais", ancoradas em estereótipos essencialistas, para a inferiorização racial, sexual, ontológica e epistemológica de povos submetidos à violência arbitrária das ocupações e do impulso dominador "civilizatório" dos movimentos coloniais, insuflados pelas "hierarquias raciais, binárias e essencialistas do fundamentalismo eurocêntrico hegemônico" (GROSFOGUEL, 2011, p. 346).

No decurso desses processos complexos de dominação e conflito, entretanto, são gestadas e acionadas resistências que interrogam os pactos civilizatórios, as concepções hegemônicas e as estruturas de saber-poder da colonialidade. Interrogações múltiplas, diversas e multifacetadas, que ganham corpo nas vozes insurgentes e nas reexistências que insistem em contestar o instituído. Nesse contexto, a perspectiva decolonial redimensiona narrativas e práticas, contrapondo aos processos de subalternização a afirmação de outras corpo-políticas do conhecimento, fruto das lutas históricas contra o racismo/sexismo/universalismo abstrato. Atentar a isso, segundo Noguera (2014, p. 34), significa afirmar que "existem vários universos culturais, não existe um sistema único organizado em centro e periferias, mas um conjunto de sistemas policêntricos em que centro e periferias são contextuais, relativos e politicamente construídos".

É nesse horizonte que a Lei 10.639/03, que alterou a Lei de Diretrizes e Bases da Educação Nacional, torna-se um marco simbólico e político importante na trajetória de lutas do Movimento Negro brasileiro. A Lei, que tornou obrigatória a inclusão de História e Culturas africana e afrobrasileira nos currículos escolares de todos os níveis de ensino no país, é fruto não só de inúmeros debates e embates acerca do apagamento dos referenciais culturais e da história da diáspora africana no Brasil, mas da disputa travada em torno da memória política e do necessário tensionamento de cânones eurocêntricos. Esses paradigmas operam as engrenagens daquilo que a filósofa Sueli Carneiro (2005), em diálogo com Boaventura de Sousa Santos, chamou de epistemicídio, ao 
nomear o procedimento de sistemática aniquilação subjetiva e epistêmica de sujeitos, sufocados pelas tramas coloniais:

Sendo, pois, um processo persistente de produção da inferioridade intelectual ou da negação da possibilidade de realizar as capacidades intelectuais, o epistemicídio nas suas vinculações com as racialidades realiza sobre seres humanos instituídos como diferentes e inferiores uma tecnologia que integra o dispositivo de racialidade/biopoder, e que tem por característica específica compartilhar características tanto do dispositivo quanto do biopoder, a saber, disciplinar/normatizar e matar ou anular (CARNEIRO, 2005, p. 97).

Poderíamos afirmar, igualmente, que o silenciamento de referências, vozes, bibliotecas e repertórios negros respalda-se no racismo epistêmico, que amplia e alarga os efeitos da colonialidade do saber, no que concerne à produção invalidada de conhecimentos e de filosofias desconsideradas. De acordo com Grosfoguel (2011, p. 102):

El racismo epistémico se refiere a una jerarquía de dominación colonial donde los conocimientos producidos por los sujetos occidentales (imperiales y oprimidos) dentro de la zona del ser es considerada a priori como superior a los conocimientos producidos por los sujetos coloniales no-occidentales en la zona del no-ser. [...], considerado universalmente válido para todos los contextos y situaciones en el mundo.

Ao mobilizar o repertório forjado pela filosofia decolonial para discutir os desafios e dilemas atuais na reavaliação e no reposicionamento das bases do ensino de filosofia, busca-se implicar as ações didáticas e as práticas educativas no desfazimento das estruturas de dominação, que não estão dissociadas do trabalho docente e da economia de saberes que movimentam, tampouco das relações sociais/raciais/sexuais que são reforçadas ou reconfiguradas nos processos de ensino.

Desafiar as hierarquias epistêmicas e os postulados ocidental-cêntricos é tarefa incontornável na construção da justiça cognitiva e racial, na medida em que "a colonialidade é um dos elementos constitutivos e específicos do padrão mundial do poder capitalista. Se funda na imposição de uma classificação racial/étnica da população mundial como pedra angular deste padrão de poder" (QUIJANO, 2007, p. 93). Daí a perspectiva decolonial redimensionar a questão colonial, apontando no apagamento das produções de matrizes africanas, ameríndias e afrobrasileiras os rastros e as permanências do racismo, do colonialismo e do patriarcalismo, que configuram a economia dos saberes globalizados desde Europa. E que culminam por suplantar as culturas e saberes locais, sobretudo do Sul, impondo a elas os critérios valorativos eurocentrados (REIS; CALADO, 2020).

O ponto nodal dessa discussão é a desnaturalização de uma perspectiva privilegiada de construção e formalização da história da filosofia e de seu ensino, bem como do sujeito "universal", historicamente forjado, que lhe é correlato. Desestabilização que aponta para perda de referentes unívocos e para outros agenciamentos de experiências de pensamento, quando o ensino de filosofia passa a ser encarado como questão epistêmica, filosófica e política, e não exclusivamente pedagógica. Não seria fortuito dizer que as contestações de grupos historicamente proscritos do rol dessa história eurocêntrica produzem rachaduras na autoimagem que a filosofia constituiu para si mesma como saber universal, aberto ao novo e às indagações permanentes que redimensionam o seu campo e o escopo de seus problemas. De um lado, há aqueles que recusam peremptoriamente o exercício dialógico com outras lógicas e constelações de pensamento; há quem prefira, de outro, 
permanecer incólume aos tensionamentos críticos, sob o risco de perder-se em meio a pautas que julgam demasiado identitárias, como se os referenciais hegemônicos fossem o parâmetro de medição "neutra" do grau de filosoficidade dos discursos e saberes.

No que concerne às Diretrizes Curriculares Nacionais dos Cursos de Graduação em Filosofia, o parecer n. 492/2001 do CNE/CSE, aprovado de 03 de abril de 2001, estabeleceu o perfil dos formandos; as competências e habilidades; os conteúdos curriculares; a organização e estruturacãa do curso; diretrizes para estágios e atividades complementares; e a conexão com a avaliação institucional. Quanto às disciplinas do curso, o documento afirma que:

O elenco tradicional das cinco disciplinas básicas (História da Filosofia, Teoria do Conhecimento, Ética, Lógica, Filosofia Geral: Problemas Metafísicos - além de duas matérias científicas), tem se comprovado como uma sábia diretriz. Tal elenco vem permitindo aos melhores cursos do País um ensino flexível e adequado da Filosofia. Entretanto, tendo em vista o desenvolvimento da Filosofia nas últimas décadas, algumas áreas merecem ser consideradas, como: Filosofia Política, Filosofia da Ciência (ou Epistemologia), Estética, Filosofia da Linguagem e Filosofia da Mente. No caso da licenciatura, deverão ser incluídos os conteúdos definidos para a educação básica, as didáticas próprias de cada conteúdo e as pesquisas que as embasam (BRASIL, 2001, p. 4-5).

Note-se que, no plano formal de ensino, o documento não define os temas, conteúdos e competências a serem desenvolvidos nas disciplinas. Cabe à universidade, à coordenação do curso e aos conselhos deliberativos essa tarefa, com ênfases, ementas e abordagens variadas. O que uma análise mais detida dos eixos estruturantes dos cursos de filosofia deixa entrever, contudo, é que os currículos das instituições brasileiras respaldam-se nas políticas curriculares oficiais para justificar a seleção, a organização e os recortes privilegiados. São esses os conteúdos que serão avaliados, por exemplo, nos Exames Nacionais de Desempenho de Estudantes do Ensino Superior (ENADE), com reflexos evidentes no ensino de filosofia no ensino médio ${ }^{2}$, na medida em que as avaliações nacionais reconhecem apenas os repertórios euronorteamericanos como legitimamente filosóficos, isto é, o paradigma, por excelência, da filosofia. $\mathrm{E}$ acentuam o silêncio em relação às produções brasileiras, latino-americanas e africanas. Como salientam Nascimento e Botelho (2010, p. 79):

A aquisição dessas competências e habilidades está vinculada a um padrão de excelência a ser atingido. E efetivamente quem atinge esses padrões (mais precisamente quem mais se aproxima deles) está em uma posição socialmente superior a quem não os atingem ou deles não se aproximam. Apesar de os discursos sobre competencias e habilidades afirmarem que a experiência da/o educanda/o é fundamental para o processo de aprendizagem e para a sua boa convivência na vida social, o que elas efetivam é um espaço competitivo que padroniza e hierarquiza sujeitos. Os saberes locais - que cada vez são mais

\footnotetext{
${ }^{2}$ É surpreendente, nesse sentido, como as Orientações Curriculares Nacionais para o Ensino Médio (OCNEM), de 2006, desconsideram o artigo 26-A da Lei 10.639/03, que alterou a Lei de Diretrizes e Bases da Educação Nacional (Lei n. 9.394/96), para incluir a obrigatoriedade do ensino de história e cultura africana e afro-brasileira nos currículos da educação básica. O descumprimento do que é determinado por um dispositivo legal evidencia como as tramas da colonialidade do saber seguem em curso, fundamentando o desenho dos currículos de filosofia oficiais e a manutenção da diferença colonial. Cf. BRASIL. Ministério da Educação. Orientações Curriculares Nacionais para o Ensino Médio. Ciências Humanas e suas Tecnologias. Brasília: MEC/SEB, 2006.
} 
comprometidos com pensar caso a caso, resolver cada problema com as ferramentas que a experiência possibilitar - são vistos como supersticiosos [...].

Daí a necessária indagação de desenhos e políticas curriculares. E a importância, no ensino de filosofia, de não reduzir o currículo à "ordem do discurso" monocultural, que nega outros paradigmas epistemológicos e modos de existência, para perpetuar a crença segundo a qual todas “as populaç,oes que vivam fora do pequeno espaço que é conhecido como 'Europa ocidental' sejam portadoras de um tipo de saber inferior, de uma interpretação inferior do mundo, de uma espiritualidade inferior, notadamente marcada pelo folclore e pela superstição, e não pela 'verdade'." (NASCIMENTO, 2013, p. 4). Assim, deveria causar estranheza a quase inexistência de vozes negras, ameríndias e femininas nos currículos de filosofia, bem como de filósofos/as nacionais e latino-americanos/as. O que revela, por sua vez, o centramento em um lócus epistêmico exclusivamente masculino e europeu, na medida em que o sistemático silenciamento "destas produç,ões é uma explicitação do modo como a colonialidade do saber é constitutiva dos currículos não apenas do ensino superior de filosofia, mas também de uma proposta colonial para a constituição dos currículos do ensino médio” (NASCIMENTO; BOTELHO, 2010, p. 83-84).

Não se trata, é certo, de negar o repertório filosófico europeu ou norte-americano, mas, sim, de questionar silenciamentos, pactos narcísicos e ausências que pautam a desconsideração de filosofias e pensadores/as proscritos/as a um lugar epistêmico subalterno. É aí que a crítica endereçada à monocultura do pensamento europeu, que delimita as fronteiras dos latifúndios do saber filosófico, direciona-se ao necessário alargamento das racionalidades, das lógicas, das constelações de saberes e dos currículos, que não se esgotam na monofonia de uma única matriz epistêmica/epidérmica. É preciso, portanto, atentar-se "às armadilhas que estas teorias podem trazer, ainda mais quando elas são feitas sob a condução da colonialidade que domina sob a égide do desenvolvimento, do progresso e, por que não, em nome de um suposto benefício para as sociedades menos favorecidas" (NASCIMENTO; BOTELHO, 2010, p. 76).

Conforme indica Grundy (apud SACRISTÁN, 2000, p. 14), "o currículo não é um conceito, mas uma construção cultural. Isto é, não se trata de um conceito abstrato que tenha algum tipo de existência fora e previamente à experiência humana. É, antes de tudo, um modo de organizar uma série de práticas educativas". Se o currículo é uma construção cultural, cujos modos de organização variam politica e historicamente, ele estabelece uma “[...] ligação entre a cultura e a sociedade exterior à escola e à educação; entre o conhecimento e cultura herdados e a aprendizagem dos alunos; entre a teoria (ideias, suposições e aspirações) e a prática possível, dadas determinadas condições" (SACRISTÁN, 2000, p. 61). E, evidentemente, é objeto, espaço e lugar de disputas, no confronto entre diferentes projetos de sociedade, de educação e de poder.

Se há uma lacuna produzida na formação de estudantes e professores/as, como vazio que reitera o não-lugar destinado ao pensamento e às experiências extra-ocidentais, não é de estranhar que isso reverbere nas práticas docentes na educação básica e na educação superior. $\mathrm{O}$ círculo vicioso resulta na consolidação da hegemonia filosófica da modernidade/colonialidade europeia, autorreferenciada, minando a potência significativa - e significante - de filosofias produzidas desde o Sul, em articulação com a localização corpo-política dos sujeitos. E que culmina por reiterar, no imaginário coletivo, a imagem da filosofia apartada da realidade, das lutas sociais e das disputas entre diferentes valores civilizatórios e projetos societários, incapaz de dialogar com o território e seu entorno.

A hierarquização das culturas e humanidades não é produzida somente no plano documental e curricular. A periferização do mundo extra-ocidental e seu reflexo no campo epistemológico produzem zonas de não-ser (FANON, 2008), onde o dispositivo de racialidade 
"realiza as estratégias de inferiorização intelectual do negro ou sua anulação enquanto sujeito de conhecimento, ou seja, formas de sequestro, rebaixamento ou assassinato da razão. Ao mesmo tempo, e por outro lado, o faz enquanto consolida a supremacia intelectual da racialidade branca" (CARNEIRO, 2005, p. 10). A liquidação sistemática no plano epistêmico só pode ser sustentada, então, por uma razão racializada, que destitui a capacidade de pensamento de sujeitos não brancos, aos quais é imposta a assimilação cultural, enquanto opera a desqualificação, o sequestro e o rebaixamento de suas produções, conhecimentos e experiências.

Nos antípodas dos projetos de extermínio, vilipêndio e silenciamento de corpos negros, a Lei 10.639/03, fruto do protagonismo do Movimento Negro nas lutas travadas em nome de um projeto de educação antirracista e racialmente igualitário, tem como destinatária toda a sociedade brasileira. O desafio de promover relações raciais equânimes exige uma crítica filosófica da própria história da filosofia, de seu ensino e de seu currículo hegemônico. Pois, na medida em que as relações de poder assimétricas que circulam nos currículos são tensionadas, bem como as instituições e os imaginários, explicitam-se tanto a parcialidade e os valores civilizatórios que os configuram como, de outra perspectiva, que o currículo é "[...] texto, discurso e documento: documento de identidade" (SILVA, 2003, p. 150). Como documento de identidade, ele pode reforçar ou questionar imagens, símbolos, representações raciais, sociais e sexuais, (des)naturalizando relações construídas no interior de sociedades localizadas que produzem, transmitem e consagram determinados saberes, práticas e discursos:

O currículo é uma prática social pedagógica que se manifesta sempre em dois aspectos indissociáveis: como ordenamento sistêmico formal e como vivência subjetiva e social. Só é possível considerá-lo na síntese desses dois aspectos. Trata-se de uma prática social complexa que envolve construção histórica-social; disputas ideológicas; espaços de poder; escolhas culturais; e exercício de identidades (PONCE, 2018, p. 793).

No que tange ao ensino de filosofia, tanto na educação básica quanto na educação superior, a compreensão desses jogos de poder nos ajuda a reorganizar práticas pedagógicas, planos de ensino e percursos (auto)formativos, de modo a promover uma educação filosófica comprometida com a repactuação epistêmica e política, tendo por horizonte a justiça cognitiva, racial e social. Isto é, sem que haja efetivamente a implicação de docentes e a proposição de práticas pedagógicas antirracistas e antissexistas, não será possível criar "uma comunidade aberta de aprendizado" (HOOKS, 2019, p. 18) como espaço comunitário e diverso, no interior do qual a filosofia pode potencializar a sua capacidade de produzir deslocamentos, atravessamentos e de afetar. Esse espaço supõe, sem dúvida, que a filosofia seja encarnada, corporificada e capaz de se situar não como discurso impessoal, universal e abstrato, mas como conhecimento geopoliticamente situado e epistemicamente localizado.

O ensino afrorreferenciado da filosofia não visa a recentrar, de maneira unilateral ou excludente, os acervos, repertórios e bibliotecas filosóficos. Em consonância com as Diretrizes Curriculares Nacionais para a Educação das Relações Étnico-raciais e para o Ensino de História e Cultura Afro-brasileira e Africana, o ensino de filosofia comprometido em efetivar o dispositivo legal deve, como propõe Noguera, se defrontar com algumas questões:

O que é próprio da filosofia que pode contribuir para horizontes antirracistas na sociedade brasileira? O que a Filosofia tem a dizer sobre racismo antinegro? Existem pontos de contato entre a filosofia e a história da África? As culturas africanas e afrodiaspóricas, em especial a afro-brasileira, são relevantes para o entendimento da filosofia? Ou ainda, existe filosofia africana e/ou filosofia afrobrasileira? Em caso afirmativo, a africana e/ou afro-brasileira estaria(m) apta(s) a 
examinar e discorrer sobre os pontos-chave da educação das relações étnicoraciais? Enfim, este trabalho é, ao mesmo tempo, uma aposta e uma proposta de polidiálogo (NOGUERA, 2014, p. 19-20).

Trata-se de inquirir, com radicalidade, políticas curriculares, práticas pedagógicas e epistemologias para rastrear os lastros da colonialidade e do racismo nos processos educativos e nas histórias da filosofia, propondo, em seu lugar, ampliação de repertórios, estratégias que combatam injustiças cognitivas e raciais, bem como a pluriversalidade, a descolonização do pensamento e do corpus filosófico. Em que pese a manifesta importância das legislações educacionais antirracistas, as práticas a serem levadas a cabo precisam ganhar "corpo" e densidade no chão das salas de aula, nos itinerários formativos e nas proposições que contribuam efetivamente para a educação das relações étnico-raciais. Como consta no Plano Nacional de Implementação das Diretrizes Curriculares Nacionais da Educação para as Relações Étnicoraciais (BRASIL, 2009), a aplicabilidade das regulamentaç̃ões necessita ser expandida nos sistemas de ensino, pois:

[...] as instituições devem realizar revisão curricular para a implantação da temática, quer nas gestões dos Projetos Políticos Pedagógicos, quer nas Coordenações pedagógicas e colegiados, uma vez que possuem a liberdade para ajustar seus conteúdos e contribuir no necessário processo de democratização da escola, da ampliação do direito de todos e todas a educação, e do reconhecimento de outras matrizes de saberes da sociedade brasileira (BRASIL, 2009, p. 37).

Não desconsiderar as relações (tensas) entre ensino de filosofia, currículo, eurocentrismo e crítica à colonialidade é premissa fundamental para problematizar a reprodução de relações de poder assimétricas e a legitimidade epistêmica de matrizes filosóficas extra-europeias, recorrentemente apagadas e invalidadas no circuito fechado dos enquadramentos ocidentais. Para além do desenho geopolítico europeu, a filosofia e seu ensino devem colocar em questão as hierarquias e as dicotomias fundadas em um projeto civilizatório epistemicida. A contracolonização (BISPO, 2015) do pensamento, das práticas e da vida, como ação de combate à exclusão e ao silenciamento de sujeitos desumanizados, exige o confronto com geopolíticas racistas/sexistas do conhecimento. É aí que o currículo e o ensino de filosofia em perspectiva decolonial podem contribuir para deslocar o discurso eurocêntrico e rechaçar a lógica colonial-racista que sustenta a subalternização ontológica e epistêmica de grupos marginalizados, com base em critérios raciais.

\section{CONSIDERAÇÕES FINAIS}

Descolonizar os currículos, as práticas, a linguagem e o pensamento não é tarefa fácil. E se as lutas da atualidade têm apontado para a necessidade permanente - e incondicional - desse exercício, nos cabe propor ações concretas que se contraponham às práticas que reforçam a violência dos padrões coloniais/racistas/patriarcais. Essas ações epistêmico-político-pedagógicas são imprescindíveis para que se reordenem os enunciados e a estrutura racializada de poder das instituições e dos currículos. Trata-se de reconfigurar e repactuar o contrato racial forjado pelos códigos da branquitude, salientando para os efeitos de violência produzidos por ele, na medida em que a branquitude olha "para si como moralmente ideal, decente, civilizada e majestosamente generosa, em controle total e livre da inquietude que sua história causa" (KILOMBA, 2019, p. 37).

Superar hierarquizações e desigualdades raciais/sexuais exige que se partam de questões concretas e da problematização do presente histórico na reinvenção de práticas pedagógicas e 
filosóficas capazes de produzir resistências frente aos controles tácitos e manifestos que funcionam como crivos legitimadores do que é ou não filosofia, do que deve ou não ser ensinado como norma do campo. E a norma do campo, evidentemente, é pautada pelo rol de referenciais forjados no interior do sistema de saber-poder europeu/branco/masculino/cristão. Esse sistema, que organiza o usufruto de privilégios epistêmicos, simbólicos e materiais, tomando como critério a supremacia racial branca, beneficia e confere vantagens aos sujeitos que partilham dessa posição de poder. A territorialidade e a autoridade racial branca, que se pretendem não racializadas, por conseguinte, chancelam a produção de conhecimentos e discursos em chave universal, isto é, elaborados pelo grupo que representa a norma, o normal e a normalidade. Esses privilégios ancoram-se na partilha de uma identidade e de um conjunto de referências e valores que só podem trazer vantagens a alguns à medida que acarretam prejuízos a outros, aprofundando desigualdades e opressões.

É preciso, portanto, reconfigurar diretrizes de ensino, desenhos curriculares, estratégias institucionais e formativas, a fim de cumprir o disposto pelas legislações antirracistas e, sobretudo, realizar o que é suposto pelo trabalho filosófico, isto é, a desconstrução de paradigmas e parâmetros que não dão conta do que é o ensino de filosofia, tampouco do que deva ser, em perspectiva monorracional ou universal, pautado por referenciais inquestionáveis. Desfazer privilégios, silêncios e compreensões hegemônicas é tarefa crucial para potencializar os corpos politizados do conhecimento e tornar manifestos os jogos de poder nas escrituras/estruturas curriculares.

Pluralizar concepções, experiências e representações nos currículos, no ensino de filosofia e na filosofia da educação é compreender a diversidade de territórios epistêmicos como elemento constitutivo de todos os grupos e sociedades, e ferramenta essencial para uma educação intercultural que colabore no enfrentamento ao racismo e ao sexismo epistêmicos. A discussão acerca das relações étnico-raciais e o combate a todas as formas de discriminação devem caminhar conjuntamente, atrelados a práticas pedagógicas comprometidas com uma educação antirracista, antissexista e anticlassista.

Daí o desafio que nos coloca diante do necessário redimensionamento do campo e das práticas, na abertura de horizontes que apontam para lugares plurais de enunciação e de produção de conhecimento, que instabilizam vozes monofônicas e impositivas. O exercício de produção de rachaduras e movimentos de diferenciação no ensino de filosofia se traduz na exigência ética, estética, político-pedagógica e epistemológica de não conceber como neutro o campo de forças geopolítico do conhecimento filosófico nem de reiterar escalas, classes e hierarquias que insistem na centralidade da Europa como lócus exclusivo da filosofia. Por isso, conforme destaca Nascimento (2020, p. 27), "uma filosofia descolonizada estaria comprometida em pensar não apenas o local, mas desde o local, pensando estratégias que, atentas ao modo eurocêntrico de produzir conhecimento e filosofia, estejam vinculadas a um projeto de liberar o pensamento das amarras deste projeto colonial".

O ensino de filosofia em bases decoloniais aponta, ainda, para a necessária contraposição ao posicionamento que desconsidera as determinações geopolíticas do contexto de produção das filosofias, como se toda filosofia não fosse produzida desde lugares específicos e configurações culturais particulares. O que se pode notar é que está em curso um processo radical de disputa de narrativas e (re)escritas da(s) história(s) da filosofia, no qual destaca-se a recusa aos paradigmas hegemônicos que instituem modos unívocos de inteligibilidade da história, da filosofia e da organização das práticas pedagógicas. Desse modo, reivindicar a pluriversalidade nos impõe questionar as monoculturas do pensamento e os latifúndios do saber, indagando a lógica que sustenta e reproduz os códigos e repertórios mais valorados. O debate, portanto, tangencia os currículos, as didáticas do ensino de filosofia e as práticas de formação docente, mas também a 
crítica aos sistemas de saber-poder que seguem fundamentando múltiplas desigualdades - dentro e fora das instituições educativas.

Contextualizar o currículo de filosofia e refletir sobre suas implicações para uma prática de ensino antirracista tornam possíveis a ampliação de narrativas, perspectivas e experiências culturais, por meio da qual a universalidade abstrata é colocada em questão. Afirma-se, portanto, que o modelo cultural de racionalidade hegemônica não anula a existência, a validade e legitimidade de outras lógicas, racionalidades e constelações filosóficas. Trata-se, sim, de assumir a responsabilidade filosófica/social/pedagógica que nos cabe, comprometidos/as com práticas educativas que contribuam nas lutas para superação das desigualdades que se retroalimentam das variadas formas de colonialidade.

\section{REFERÊNCIAS}

ADICHIE, Chimamanda Ngozi. O perigo de uma história única. Trad. Júlia Romeu. São Paulo: Companhia das Letras, 2019.

BISPO, Antônio. Colonização, quilombos: modos e significações. Brasília: Universidade de Brasília, 2015.

BRASIL. Ministério da Educação. Base Nacional Comum Curricular. Brasília: MEC, 2017. Disponível em: <http://basenacionalcomum.mec.gov.br/images/BNC C_20dez_site.pdf>. Acesso em: 10 ago. 2020.

BRASIL. Ministério da Educação. Lei 10.639, de 19 de janeiro de 2003. Altera a Lei no 9.394, de 20 de dezembro de 1996, que estabelece as diretrizes e bases da educação nacional, para incluir no currículo oficial da Rede de Ensino a obrigatoriedade da temática "História e Cultura AfroBrasileira", e dá outras providências. Disponível em: <https://www.planalto.gov.br/ccivil_03/Leis/2003/L10.639.htm>. Acesso em: 20 ago. 2020.

BRASIL. Ministério da Educação. Parecer CNE/CES 492/2001. Diretrizes curriculares nacionais dos cursos de filosofia, história, geografia, serviço social, comunicação social, ciências sociais, letras, biblioteconomia, arquivologia e museologia. Brasília: MEC, 2001. Disponível em: < http://portal.mec.gov.br/cne/arquivos/pdf/CES0492.pdf>. Acesso em: 10 ago. 2020.

BRASIL. Ministério da Educação. Plano Nacional de Implementação das Diretrizes Curriculares Nacionais da Educação das Relações Étnico-Raciais e para o Ensino de História e Cultura Afrobrasileira e Africana. Brasilia: MEC, 2009. Disponível em: $<$ http://etnicoracial.mec.gov.br/images/pdf/diretrizes_curric_educ_etnicoraciais.pdf $>$. Acesso em: 11 ago. 2020.

CARNEIRO, Aparecida Sueli. A construção do Outro como não-ser como fundamento do ser. Tese (Doutorado em Educação) - Faculdade de Educação da Universidade de São Paulo, São Paulo, 2005.

FANON, Frantz. Pele negra, máscaras brancas. Trad. Renato da Silveira. Salvador: EDUFBA, 2008.

GROSFOGUEL, Ramón. La descolonización del conocimiento: diálogo crítico entre la visión descolonial de Frantz Fanon y la sociología descolonial de Boaventura de Sousa Santos. FormasOtras, n. 1, p. 97-108, 2011.

HOOKS, bell. Ensinando a transgredir: a educação como prática da liberdade. Trad. Marcelo Brandão Cipolla. São Paulo: Editora WMF Martins Fontes, 2019. 
KILOMBA, Grada. Memórias da plantação: episódios de racismo cotidiano. Trad. Jess Oliveira. Rio de Janeiro: Cobogó, 2019.

MIGNOLO, Walter. Histórias globais/projetos locais: colonialidade, saberes subalternos e pensamento liminar. Belo Horizonte: Editora UFMG, 2003.

NASCIMENTO, Wanderson Flor do. Ensino de filosofia e filosofia africana: dimensões metafilosóficas na discussão curricular. Revista do NESEF - Filosofia e Ensino, v. 6, p. 17-25, 2015.

NASCIMENTO, Wanderson Flor do. Entre apostas e heranças: contornos africanos e afrobrasileiros na educação e no ensino de filosofia no Brasil. 1 $^{\text {a }}$. ed. Rio de Janeiro: NEFI, 2020. (Coleção Ensaios).

NASCIMENTO, Wanderson Flor do. Outras vozes no ensino de filosofia: o pensamento africano e afro-brasileiro. Revista Sul-Americana de Filosofia e Educação, v. 18, p. 74-89, 2012.

NASCIMENTO, Wanderson Flor do; BOTELHO, Denise. Colonialidade e educação: o currículo de filosofia brasileiro entre discursos coloniais. Revista Sul-Americana de Filosofia e Educacạao, n. 14, mai./out. 2010.

NOGUERA, Renato. Denegrindo a educação: um ensaio filosófico para uma pedagogia da pluriversalidade. Revista Sul-Americana de Filosofia e Educação, v. 18, p. 62-73, 2012.

NOGUERA, Renato. O ensino de filosofia e a Lei 10.639. Rio de Janeiro: Pallas/Biblioteca Nacional, 2014.

PONCE, Branca Jurema. O currículo e seus desafios na escola pública brasileira: em busca da justiça curricular. Currículo sem Fronteiras, v. 18, n. 3, p. 785-800, set./dez. 2018.

QUIJANO, Aníbal. Colonialidade do poder, eurocentrismo e América Latina. In: LANDER, Edgardo (Org.). A colonialidade do saber: eurocentrismo e ciências sociais - perspectivas latinoamericanas. Trad. Júlio César Casarin Barroso Silva. 1ª ed. Buenos Aires: CLACSO, 2005.

QUIJANO, Aníbal. Colonialidad del poder y clasificación social. In: CASTRO-GÓMEZ, Santiago; GROSFOGUEL, Ramón. (Org.). El giro decolonial: Reflexiones para una diversidad epistémica más allá del capitalismo global. Bogotá: Universidad Javeriana-Instituto Pensar, Universidad Central-IESCO, Siglo del Hombre Editores, 2007. p. 93-126.

REIS, Diego dos Santos. Saberes encruzilhados: (de)colonialidade, racismo epistêmico e ensino de filosofia. Educar em Revista, Curitiba, v. 36, p. 1-20, 2020.

REIS, Diego dos Santos; CALADO, Maria da Glória. Diálogos possíveis entre educação antirracista e decolonial: vozes insurgentes, pedagogias críticas e a Lei 10.639/03. Cadernos do Aplicação (UFRGS), Porto Alegre, v. 33, n. 2, jul-dez. 2020.

SACRISTÁN, José Gimeno. O currículo: uma reflexão sobre a prática. $3^{a}$. ed. Porto Alegre: Artmed, 2000.

SACRISTÁN, José Gimeno. Poderes instáveis em educação. Porto Alegre: Artmed, 1999.

SILVA, Tomaz Tadeu da. Documentos de identidade: uma introdução às teorias do currículo. $2^{\mathrm{a}}$. ed. Belo Horizonte: Autêntica, 2003. 


\section{Informações do(a)(s) autor(a)(es)}

Diego dos Santos Reis

Universidade Federal da Paraíba (UFPB)

E-mail:diegoreis.br@gmail.com

ORCID: https://orcid.org/0000-0001-6977-7166

Link Lattes: http://lattes.cnpq.br/4681354757357359 